\title{
Using Software's and Technology in Solving Mathematics Problem to Motivate and Accelerate the Learning Process
}

\author{
Wafaa H. Al-Hilli ${ }^{1^{*}}$ \\ ${ }^{1}$ Department of Mathematics, College of Education University of AL-Qadisiyah, IRAQ
}

Received 7 September 2018 - Revised 1 November 2018 - Accepted 25 November 2018

\begin{abstract}
The purpose of this study was to investigate the use of software and technology in solving mathematics problem for speed-up the learning process. In this research, as a case study we investigated the dynamic properties that lead to transformations into chaos, where the point of resistance and the points of proximity was studied. We discussed the solving of the problem by applying the Matlab software for the case study. It demonstrated the areas of contraction and expansion of the map as well as the points of attracting and repelling. The results showed that the use of information and communication technology in student's mathematical reasoning skill is effective. The goal of education is to transform a student into a person with high decisionmaking power and creative solving problems and has the power of reasoning. Citizenship education that can adapt to the complexity of the 21 st century.
\end{abstract}

Keywords: learning process, sensitive dependence, technology and software

\section{INTRODUCTION}

Developing students' knowledge and skills related to ICT in the school years provides an important grounding for later in life. It also provides equity of opportunity, regardless of background. General social commentary and the popular press tend to generalize about young people, their access to and use of technology. Recent literature have challenged these assumptions and acknowledge that, although students today may have been born into a technologically rich world, they may not be avid and skillful users of technology (Bennett, Maton, \& Kervin, 2008; Masalimova et al., 2017; Gorbunova \& Kalimullin, 2017; Levina et al., 2017; Kalimullin \& Utemov, 2017; Zelenina \& Khuziakhmetov, 2017; Omarova et al., 2018). Further, there is recognition that merely providing access to technology is not enough. Meaningful development of technology based knowledge and skills is important for all students, in order to avoid a phenomenon known as the 'second-level digital divide', whereby people have drastically differentiated skills, which in turn influence how people participate in society (OECD, 2010).

Dynamical systems are the branch of mathematics devoted to the study of systems governed by a consistent set of laws over time such as difference and differential equations. The emphasis of dynamical systems is the understanding to geometrical properties of trajectories and long term behavior. Over the last 40 years, with the discovery of chaos and strange attractors, dynamical systems theory has gained considerable interest and has been found to have tentacular connections with many different areas of mathematics (such as number theory and topology) and science. Dynamical systems can model an incredible range of behavior such as the motion of planets in the solar systems, the way diseases spread in a population, the shape and growth of plants, the interaction of optical pulses, or the processes that regulate electronic circuits and heart beats. Chaos is one of the few notions in mathematics which cannot usually be defined in a word or statement. Most dynamical systems are considered chaotic depending on the either the topological or metric properties of the system. Lozi map is a two-dimensional map similar to the Hénon map but with the term -a $x^{2}$ replaced by $-a|x|$. In this paper we aim to study the family of the Lozi maps La, b: R2 $\rightarrow R 2, L a, b=(1+y-a|x|$, bx), and their strange attractors La, $b$.

Application of information and communication technology in education is the basis of motivation, learning, experience and innovation. Therefore, its application in education is an irrefutable necessity.

(C) 2019 by the authors; licensee Modestum Ltd., UK. This article is an open access article distributed under the terms and conditions of the Creative Commons Attribution License (http://creativecommons.org/licenses/by/4.0/). \wafaahadi23@yahoo.com (*Correspondence) 


\section{Contribution of this paper to the literature}

- The research aims to build a new planning style that contributes to the dynamic response of the educational and environmental system which leads to the harmony of education with the needs of society and its changes in light of the theory of chaos.

- $\quad$ There are Alert help Solving Problem of mathematics speed-up the learning process

The experiences of countries such as Indonesia, the United States and Germany represent the planning of the government of these countries for the development and introduction of a curriculum based on ICT. Since 2001, the Indonesian government has developed a five-year plan for the development and implementation of information and communication technology in education, and based on the use of information and communication technology as a tool for learning curricula in educational centers, schools and Universities are recognized as essential. The US government has also devoted its most important chapter to its technological development, and in this regard, the expansion of information and communication highways is considered to be the most important part of the realization of this issue.

\section{METHODOLOGY}

The method of this research is a descriptive survey carried out in a survey method. Subjects of study were all elementary school teachers in Baghdad who were studying in the second semester. A sample of 88 people was selected based on Krejcie and Morgan's tables, which were selected by simple random sampling. A researchermade questionnaire was used to collect the required information. It contained 24 closed-ended questions in the field of the five variables studied, including changing attitude, reasoning, creativity (with 5 questions each) and fixing (with 4 questions). In the five-option range, Likert was designed with response levels (very high, high, low, very low). In this questionnaire, teachers' viewpoints on the impact of information and communication (in this research, in particular, on the use of communication tools and tools, such as software) on the consolidation and sustainability of course content, reasoning skills, active learning, creativity, attitude change and Ultimately, learning in its general sense has been studied.

In the following, we introduce a method to compute the largest Lyapunov exponent for the family of plane maps, known as Lozi maps, from the symbolic of its attractor. As Lozi in 1978 pointed out numerically, a certain piecewise linear plane map displayed a strange attractor. We call the two-parameter family of piecewise affine homeomorphisms, the Lozi family of maps. Any pair $\left(\begin{array}{l}x \\ y\end{array}\right)$ for which $\mathrm{f}\left(\begin{array}{l}x \\ y\end{array}\right)=\mathrm{x}$ and $\mathrm{g}\left(\begin{array}{l}x \\ y\end{array}\right)=\mathrm{y}$ is said a fixed point of the two dimensional dynamical system. Let $\mathrm{V}$ be a subset of $\mathrm{R} 2$ and $V_{0}=\left(\begin{array}{l}x \\ y\end{array}\right)$ be any element in $\mathrm{v}$ Consider $\mathrm{L}: \mathrm{V} \rightarrow \mathrm{R}^{2} \mathrm{a}$ map. Furthermore, assume that the first partials of the coordinate maps $l_{1}$ and $l_{2}$ of $F$ exist at $v_{0}$ is the linear map DL $\left(\mathrm{v}_{0}\right)$ defined on $\mathrm{R}^{2}$ by $\mathrm{DL}$

$\left(\mathrm{v}_{0}\right)=\left[\begin{array}{cc}\frac{\partial \mathrm{l} 1\left(\mathrm{v}_{0}\right)}{\partial \mathrm{x}} & \frac{\partial \mathrm{l} 1\left(\mathrm{v}_{0}\right)}{\partial \mathrm{y}} \\ \frac{\partial \mathrm{l} 2\left(\mathrm{v}_{0}\right)}{\partial \mathrm{x}} & \frac{\partial \mathrm{l} 2\left(\mathrm{v}_{0}\right)}{\partial \mathrm{y}}\end{array}\right]$ For all $\mathrm{v}_{0}$ in $\mathrm{V}$ the determine of $\mathrm{D}_{\mathrm{L}}\left(\mathrm{v}_{0}\right)$ is called the Jacobian of $\mathrm{L}$ at $\mathrm{v}_{0}$ and is denoted by $\mathrm{J}=\operatorname{det} \mathrm{DL}\left(\mathrm{v}_{0}\right)$. Let $\mathrm{L}: \mathrm{R}^{2} \rightarrow \mathrm{R}^{2}$ be a map and $\mathrm{v}_{0} \in \mathrm{R}^{2}$, if $\left|\mathrm{JL}\left(v_{0}\right)\right|<1$, then $\mathrm{L}$ is called area contracting at $\mathrm{v}_{0}$, if $\left|\mathrm{JL}\left(v_{0}\right)\right|>$ 1 then $\mathrm{L}$ is called area expanding at $\mathrm{v}$ The map is called a diffeomorpism if achieved: ( one - to - one , onto , $\mathrm{C}^{\infty}$ and its inverse $L^{-1}: R^{n} \rightarrow R^{n}$ is $C^{\infty}$ ), the eigenvalues of $D L$ at this point is attracting if $\lambda_{1}, \lambda_{2}<1$, its repelling fixed point if $\lambda_{1}, \lambda_{2}>1$ and if $\lambda_{1}>1, \lambda_{2}<1$ the map is saddle.

\section{RESULTS}

\section{Properties of Lozi Map}

Teachers evaluate all kinds of materials that they use for teaching and learning. There are many similar considerations when evaluating technological tools, and some criteria that are unique. Some criteria and questions teachers might ask themselves when evaluating educational software, applications and resources are listed below. How relevant each of these considerations is depends on the form of the technology; for example, a digital learning resource or software that might not include instructional content.

\section{Age/year level:}

- Is the application appropriate for the age and year level of the students?

- Is the reading level of the text and type of media appropriate? 


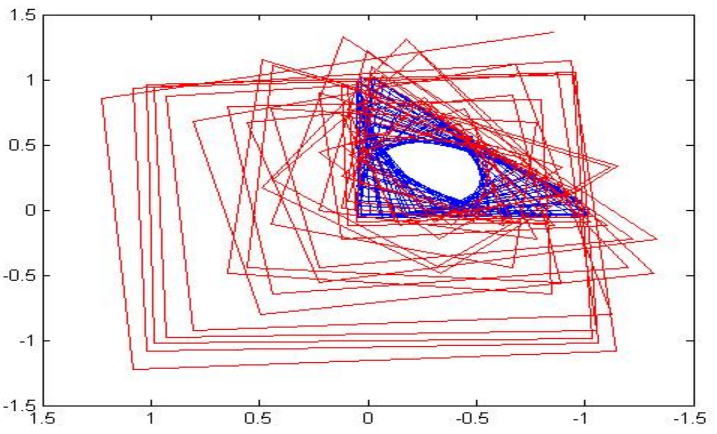

(a)

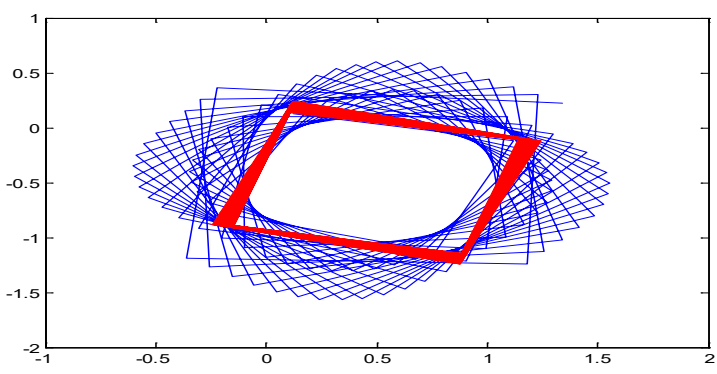

(c)

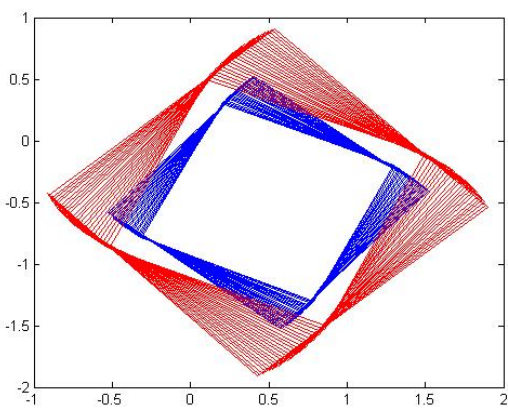

(b)

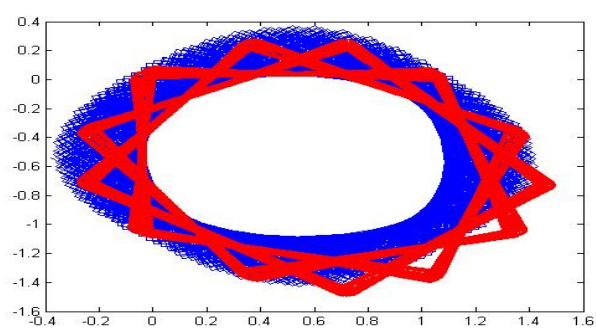

(d)

Figure 1. The Lozi map is sensitive dependence on initial conditions (a) sensitive dependence on initial conditions with $x 1=0.5$; $\mathrm{y} 1=0.7 ; \mathrm{a} 1=1 ; \mathrm{b} 1=-1.002 ; \mathrm{and} \mathrm{x} 2=0.6 ; \mathrm{y} 2=0.8 ; \mathrm{a} 2=1 ; \mathrm{b} 2=-1.004 ;(\mathbf{b})$ sensitive dependence on initial conditions with $\mathrm{x} 1=0.2$ $\mathrm{y} 1=0.3, \mathrm{a} 1=0.01, \mathrm{~b} 1=-1.003$ and $\mathrm{x} 2=0.2 \mathrm{y} 2=0.3, \mathrm{a} 2=0.01, \mathrm{~b} 2=-1.003$; (c) sensitive dependence on initial conditions with $\mathrm{x} 1=0.12$, $\mathrm{y} 1=0.13, \mathrm{a} 1=0.1, \mathrm{~b} 1=-1.002$ and $\mathrm{x} 2=0.11 ; \mathrm{y} 2=0.14 ; \mathrm{a} 2=0.2 ; \mathrm{b} 2=-1.002 ;(\mathbf{d})$ sensitive dependence on initial conditions with $\mathrm{X} 1$ $(1)=-0.025 ; \mathrm{y} 1(1)=0.027 ; \mathrm{a} 1=-0.1 ; \mathrm{b} 1=-1.0002 ;$ and $\mathrm{x} 2(1)=-0.026 ; \mathrm{y} 2(1)=0.028 ; \mathrm{a} 2=-0.3 ; \mathrm{b} 2=-1.0004$;

\section{Curriculum links:}

- Are there links between the content/functions of the application and the expectations of the curriculum?

- Are the content and examples relevant to the curriculum?

- Will this help teach the curriculum in new or different ways?

\section{Instructional content:}

- Is the information accurate, complete and current?

- Are sources reliable?

- Does the content encourage higher-order thinking?

- Is the content culturally appropriate? Does it present multiple perspectives?

Engaging and interactive:

- Will the learner(s) be actively involved in using the tool?

So we used software Matlab for solving the case study. Following its results for the solved problrm and its stability. We keep the overall properties of the Lozi map, including hyperbolicity and piecewise smoothness with two pieces, left and right. However, she study fixed point, diffeomorphism, we find area contracting and expanding.

The most important threads that Gulick (1992) addresses in his definition of chaos in the definition of sensitive on initial conditions which ensures. The vague notion of chaos has attracted much attention in recent years and several authors have tried to formalize it in various ways. One popular such attempt uses the definition of "sensitive dependence on initial conditions".

Let $(X, d)$ be a metric space.A map $\mathrm{f}:(X, \mathrm{~d}) \rightarrow(X, \mathrm{~d})$ is said to be sensitive dependence on initial conditions if there exit $\varepsilon>0$ such that for any $x_{0} \in X$ and any open set $U \subseteq X$ containing $x_{0}$ there exists $y_{0} \in U$ and nE $Z^{+}$such that $d\left(f^{n}\left(x_{0}\right), f^{n}\left(y_{0}\right)\right)>\in$ that is $\exists \in>0, \forall x,>0, \exists y \in B_{0}(x), \exists n \in N, d\left(f^{n}\left(x_{0}\right), f^{n}\left(y_{0}\right)\right)>\varepsilon$ Although, there is no universal agreement on definition of chaos, it is generally agreed that a chaotic dynamical system should exhibit ,we will define an ordering on $R^{n}$ (Hirsch et al., 2004). 


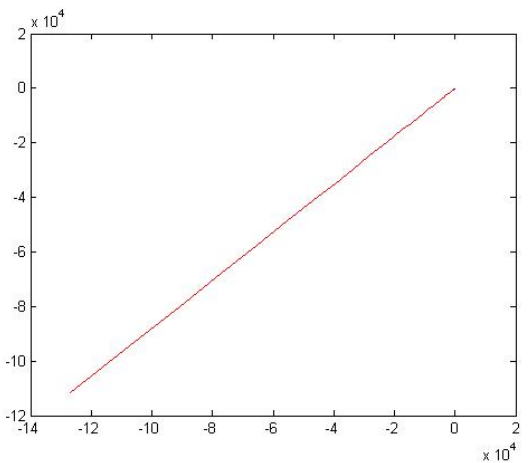

(a)

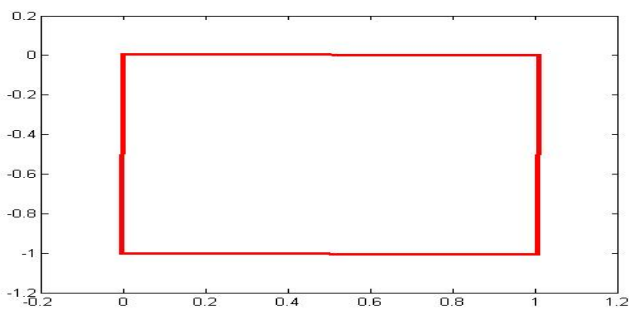

(b)

Figure 2. Not sensitive dependence on initial condition (a) $x 1(1)=0.0015 ; y 1(1)=0.0017 ; a 1=0.2 ; b 1=1.02 ;$ and $x 2=0.0016 ; y 2$ $=0.0018 ; \mathrm{a} 2=0.3 ; \mathrm{b} 2=1.04 ;(\mathrm{b}) \mathrm{x} 1=0.0015 ; \mathrm{y} 1=0.0017 ; \mathrm{a} 1=0 ; \mathrm{b} 1=-1.00032 ;$ and $\mathrm{x} 2=0.0016 ; \mathrm{y} 2=0.0018 ; \mathrm{a} 2=0 ; \mathrm{b} 2=-1.00034$;

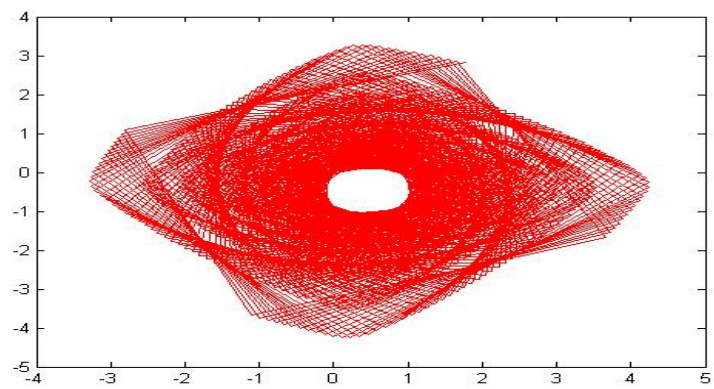

(a)

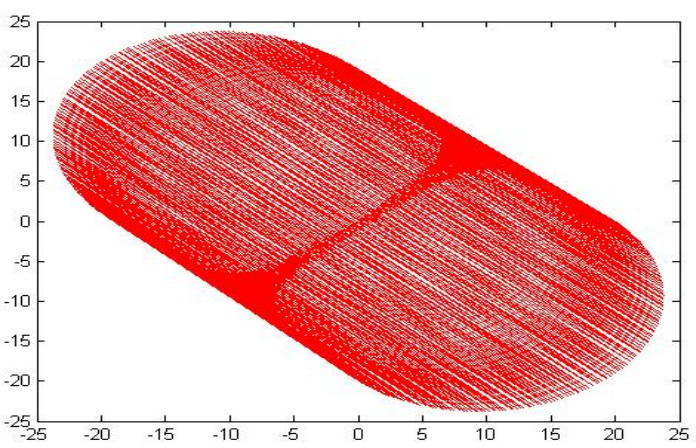

(c)

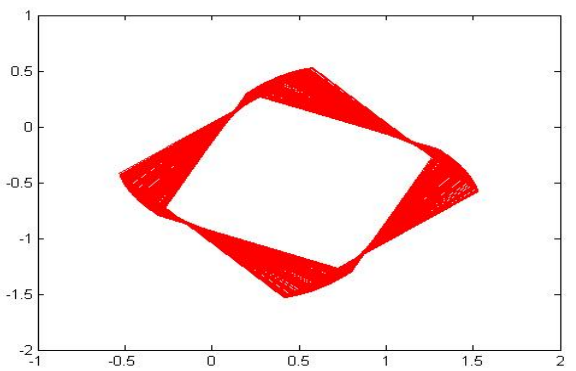

(b)

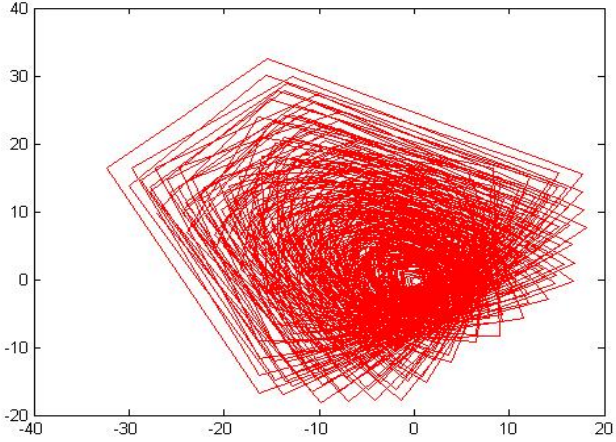

(d)

Figure 3. Case study (a) Transitive with $x=0.02 ; y=0.03 ; a=0.12 ; b=-1.003 ;(b)$ Transitive with $x=0.02 ; y=0.03 ; a=0.0016 ; b=-$ 1.0003; (c) Transitive with $x=0.2 ; y=0.3 ; a=0.1 ; b=1 ;(d)$ Transitive with $x=0.02 ; y=0.03 ; a=1.016 ; b=-1.03$;

Let $\mathrm{f}: \mathrm{X} \rightarrow \mathrm{X}$ be a dynamical system. If for every pair of nonempty open sets $\mathrm{U}$ and $\mathrm{V}$ in $\mathrm{X}$, there is a $\mathrm{n} \in \mathrm{N}$ such that $f^{n}(U) \cap V \neq \varnothing$, then $\mathrm{f}$ has topologically transitive.

Many times, the system is used to be transitive if there is an $x_{0} \in X$ such that $\overline{O\left(x_{0}\right)}=\mathrm{X}$ (i.e) f has a dense orbit).

Both of as these definitions of transitivity are equivalent, in a wide class of spaces, including all connected compact metric spaces. Then we study the sensitivity dependence on initial condition of map by varying the point $\left(x_{i}, y_{i}\right)$ as follows $(\mathrm{i}=1,2)$ control parameters $(\mathrm{a}, \mathrm{b})$ by using (Matlab) (Manning, 1975). 


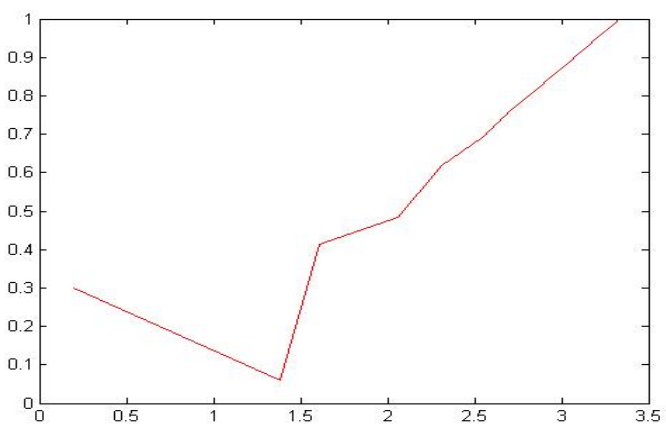

(a)

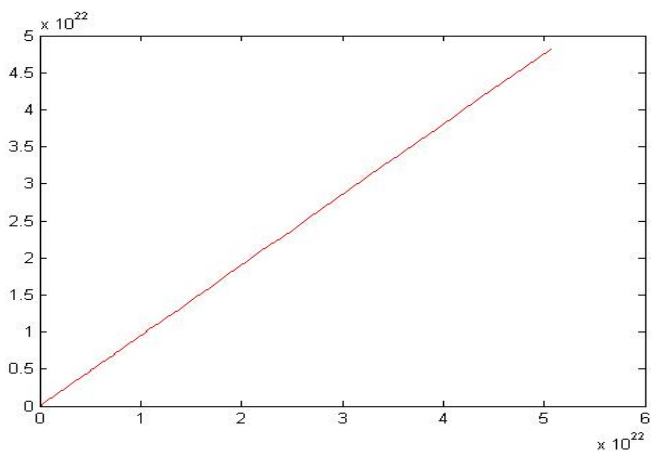

(c)

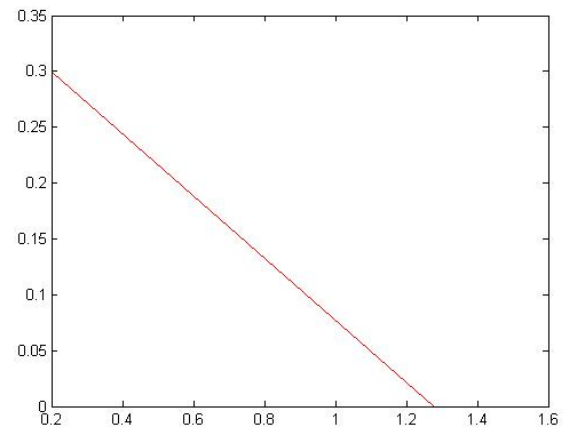

(b)

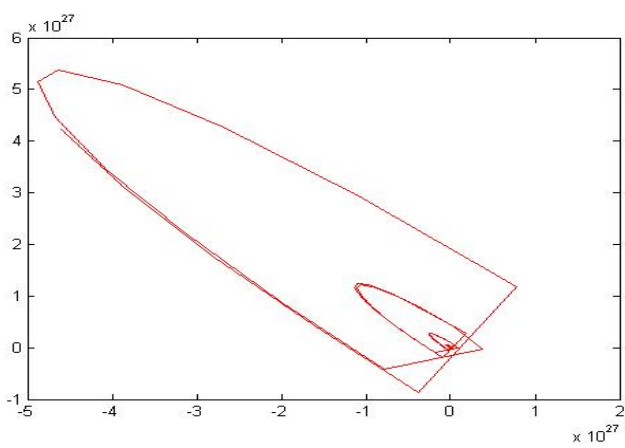

(d)

Figure 4. Not transitive (a) Not Transitive with $x=0.2 ; y=0.3 ; a=0.4 ; b=0.3 ;(b)$ Not Transitive with $x=0.2 ; y=0.3 ; a=0.1 ; b=0 ;(c)$ Not Transitive with $x=0.2 ; y=0.3 ; a=-0.1 ; b=1 ;(d)$ Not Transitive with $x=0.2 ; y=0.3 ; a=2 ; b=-1.1$;

The pace of technological change in society and in schools has been exponential and will continue to be so. Teachers are using ICT to support their role in providing students with structure and advice, monitoring their progress and assessing their accomplishments. When students use technology to conduct research projects, analyse data, solve problems, design products and assess their own work, they work with others to create and communicate new knowledge and understandings. This chapter has presented a range of tools and a range of teaching and learning strategies. These strategies are based on theories of learning that allow teachers to provide different experiences for their students. Technology is changing all the time and what we know about how to use that technology effectively is developing continuously. As a future teacher, you will continue to develop your understanding and practice regarding the use of technology to help your students learn effectively.

\section{CONCLUSION}

The results showed that the use of information and communication technology is effective in changing students' attitude toward mathematics. In the available records, there is no case comparable with this finding. But since one of today's problems in the field of education is the lack of students' interest in learning some of the lessons of mathematics, and since any kind of attitude, both positive and negative, in this field, especially in the first years of the year Education plays a crucial role in shaping the mental structure of students and consolidating these attitudes, and it may be impossible, if converted to attitudes, to become more difficult, it is necessary for the education organization to be the culminator of progress in Different arenas are, fundamental changes in the attitude of students towards a basic course of mathematics such as math The use of information and communication technology-based techniques is an interest in these lessons in learners. The result of this study also indicated that the use of information and communication technology in mathematical education could create a change in attitude. We have testified some results related to a new piecewise smooth two dimensional discrete chaotic map as a unified chaotic system that contains the original Lozi map, which has robust homoclinic chaos over a portion of its key system parameters. It was concluded that a chaotic system with a nonstationary diffusion satisfies a nonlinear dispersion law. This law leads to instabilities in a phase space. So, it was shown that the students learning and teaching efficacy will increase about 20 percent for the solved case study in Matlab software in comparison to conventional teaching and learning systems. According to the findings of the research, suggestions for the development of the use of information and communication technology in learning are presented: 
1. Focus on the culture of the concept, necessity and ways of using ICT in the curriculum of schools, especially in mathematics, due to the effect of changing the attitude, stabilization and content of the lessons, the power of reasoning, creativity, and knowledge learning

2. Development of knowledge and transformation in the attitude of mathematical teachers towards the use of information and communication technology through quality training courses.

3. Cultivating and creating a positive attitude towards the design and application of teaching technology by teachers, especially in mathematics.

4. Establishing an institute for the design, measurement, design, and notification, processing and dissemination of information and communication technology at an elementary level.

5. Creating backgrounds in curriculum and tutorials, especially mathematical lessons for using communication networks and electronic media.

6. Make necessary changes to the curriculum of schools, including math lessons tailored to the needs and expectations of today's society.

7. Investing and planning for the development of information and communication technology in elementary schools.

8. Strengthening the human resources training infrastructure in relation to information and communication technology.

9. Support and encouragement of skilled and skilled mathematical subject literacy for the production of educational software related to math education.

10. Encourage and encourage professionals to design software that is comprehensive in covering mathematical topics.

\section{REFERENCES}

Armitage, S., \& Leary, R. (2003). E-Learning series: A guide for learning technologist. Heslington Generic Center.

Gorbunova, N. V., \& Kalimullin, A. M. (2017). Simulation of the Process of Training the Future Primary School Teachers for Organizing Extracurricular Activities. Elementary Education Online, 16(4), 1860-1872. https:/ / doi.rg/10.17051/ilkonline.2017.348973

Gulick, D. (1992). Encounters with Chaos. New York: McGraw-Hill, Inc.

Hirsch, M. W., Smale, S., \& Devaney, R. L. (2004). Differentiable Equations, Dynamical Systems \& An Introduction to Chaos. USA: Elsevier.

Kalimullin, A. M., \& Utemov, V. V. (2017). Open Type Tasks as a Tool for Developing Creativity in Secondary School Students. Interchange, 48, 129-144. https:/ / doi.org/10.1007/s10780-016-9295-5

Levina, E. Y., Masalimova, A. R., Kryukova, N. I., Grebennikov, V. V., Marchuk, N. N., Shirev, D. A., Renglikh, K. A., \& Shagieva, R. V. (2017). Structure and Content of e-Learning Information Environment Based on GeoInformation Technologies. EURASIA Journal of Mathematics, Science and Technology Education, 13(8), 50195031. https:// doi.org/10.12973/eurasia.2017.00974a

Masalimova, A. R., Levina, E. Y., Platonova, R. I., Yakubenko, K. Yu., Mamitova, N. V., Arzumanova, L. L., Grebennikov, V. V., \& Marchuk, N. N. (2017). Cognitive Simulation as Integrated Innovative Technology in Teaching of Social and Humanitarian Disciplines. EURASIA Journal of Mathematics, Science and Technology Education, 13(8), 4915-4928. https:/ / doi.org/10.12973/eurasia.2017.00973a

Misiurewicz, M., \& Štimac, S. (2016). Symbolic dynamics for Lozi maps. Nonlinearity, 29(10), 30-31. https:/ / doi.org/10.1088/0951-7715/29/10/3031

Nagar, A., \& Kannan, V. (2018). Topological Transitivity for Discrete Dynamical System.

Omarova, L. B., Kalimullin, A. M., Grudtsina, L. Y., Korzhuev, A. V., \& Zhukova, M. Y. (2018). Philosophical anthropology in postmodernism. XLinguae, 11(3), 76-85. https:/ / doi.org/10.18355/XL.2018.11.03.07

Unesco. (2004). ICT in Regional Country Australia, Afghanistan, Bangladesh Cambodia, Bhutan, China, Hong Kong, India, Indonesia, North Korea, South Korea, Malaysia, Myanmar, Pakistan, New Zealand, Philippines, Samoa Vietnam, Italian, Srilanka. Retrieved from http:/ / www.unesco.org

Zelenina, N. A., \& Khuziakhmetov, A. N. (2017). Formation of Schoolchildren's Creative Activity on the Final Stage of Solving a Mathematical Problem. EURASIA Journal of Mathematics, Science and Technology Education, 13(8), 4393-4404. https:/ / doi.org/10.12973/eurasia.2017.00934a

\section{http://www.ejmste.com}

